\title{
Contraception in the 16th century
}

\author{
Lesley Smith
}

\section{Background}

On 19 May 1536, as Anne Boleyn's head was struck from her shoulders, the air in England was thick with cries of "Witchcraft, Adultery, Incest and Treachery!". Catholic Europe must have enjoyed the juicy scandal of the death of the English queen who had lured Henry away from his first wife, the pious Catherine of Aragon, and also his peoples away from holy Rome. Meanwhile, all over Europe, many men and women were enjoying healthy sex lives and practising some surprisingly competent contraceptive techniques.

In Florence, from 1431 to 1446, the Church Council had debated a number of issues, especially celibacy. The outcome, at the end of the late medieval period, was the acceptance that marriage was officially recognised as a sacrament, and within that sacrament sexuality between husband and wife was desirous to God and society. This was a blow for celibacy, which was the late medieval ideal for the deeply religious. Sex was in fashion!

For this article, I have particularly elected to look at the contraception practices of the middle classes - typically merchants, lawyers and landowners. The subject is broader than one might think; and customs and attitudes that were quite acceptable for one social stratum were often very different in another. It is also obviously easier to find contemporary recordings of direct experience amongst the literate than to depend on the observational skills of doctors' notes or literature, including pornography. There is little doubt that anal intercourse was a common form of contraception, practised across social classes, quite simply because it was free and readily available. A frequently found euphemism for anal sex was 'back door'. Guilpin, a satirist of his day, wrote:

Since marriage, Faber's prouder than before Yfaith his wife must take him a hole lower.

There is erotic literature and poetry of the day which jokes about this. Abortion, both mechanically and herbally, was used as contraception, with evidence of surgical methods appearing during the 1100 s. References to a thinly veiled abortifacient 'to start a menses' can be found in a number of household advice books. A pair of Roman-designed brass obstetrics forceps with terrifying teeth sit on my shelf to remind me of the dead babies delivered. The design had not changed much by the late 1600s.

\section{Fruity diaphragms}

During my research studies I was particularly interested in the largely oral tradition which passed from one medievalist to another regarding the use of the tops of lemons and limes inserted into the vagina to be used similarly to the modern diaphragm. The concept of using acid had been known for a long time, both within Egyptian and Roman societies. Vinegar dipped in sponges inserted into the body crops up in other various places throughout

J Fam Plann Reprod Health Care 2006; 32(1): 59-60

Tutbury Castle, Tutbury, UK

Lesley Smith, Curator

Correspondence to: Lesley Smith, Tutbury Castle, Tutbury, Staffordshire DE13 9JF, UK. E-mail: info@tutburycastle.com

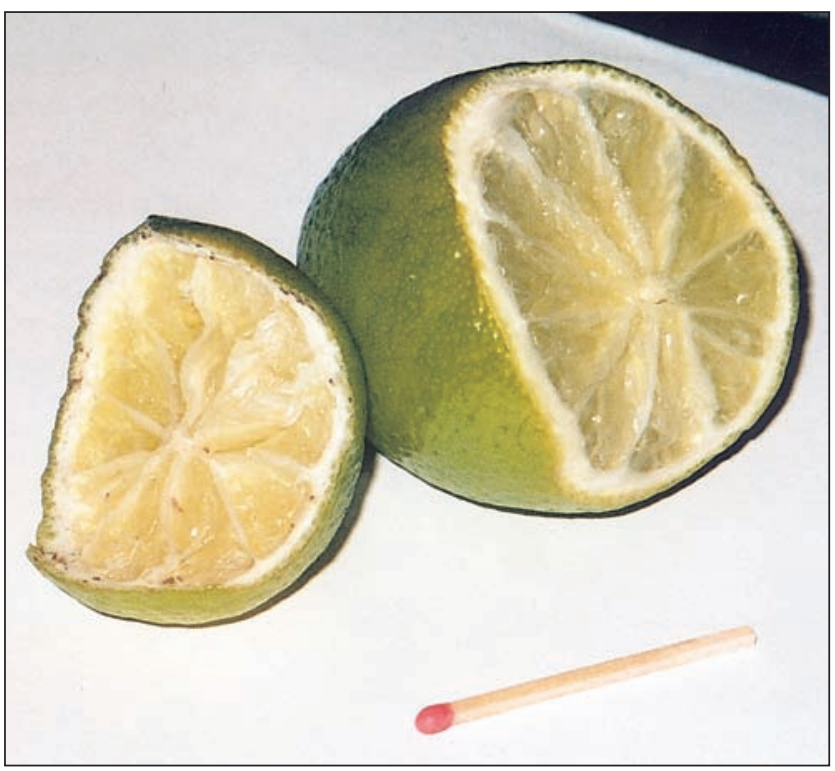

Figure 1 Lime top used by the author in the diaphragm experiment. The matchstick is only shown to give an impression of scale, and plays no part in the contraceptive method!

history. However, the specific evidence of lemons and limes being used by Tudors appears vague. Various authorities state that this was the case, but evidence is difficult to obtain. I was frankly sceptical: it sounded like it would hurt and sting, and I have come across many assertive women in the 16th century who simply would not tolerate something so uncomfortable.

Consequently, I enlisted the help of the gynaecologist, Mr Tony Roberts, to conduct an experiment that might help us understand how lemons and limes might work as a contraceptive device.

The fruit was cut into a curved shape, photographed and measured, before I inserted it into my body (Figure 1). It did not sting at all - in my personal experience. It settled comfortably over the neck of the womb (cervix) and stayed there, as confirmed by Mr Roberts. I was able to move around comfortably without feeling it, and in fact it was even more comfortable than a tampon. Pressure from a finger was still comfortable, and there is no reason to think that intercourse might be uncomfortable with the fruit in position. The juice kills sperm and candida and, I am told, most forms of venereal disease would not prosper in such an unnaturally acid environment (Box 1). You have the physical barrier of the fruit and a second physical barrier as the neck of the womb becomes slightly tight and swollen from the acid in the juice. I kept the fruit in all night and was able to remove it the next day without any difficulty.

Box 1: Citrus fruit as a contraceptive device
Lemon juice
Lime juice
Vagina
NB. The higher the pH value, the more alkaline the environment. A pH
of 7.8 is needed for the optimum migration of sperm in cervical mucus.
Below pH 6.9 sperm die, the rate of death increasing with decreasing
pH. In environments with a pH of 4.0 or less sperm die very rapidly.




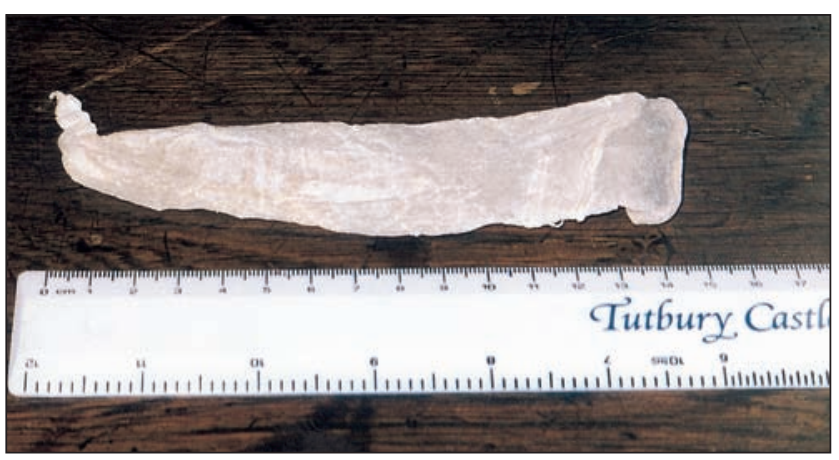

Figure 2 Example of a 16th century gut condom (courtesy of The British Museum, London, UK).

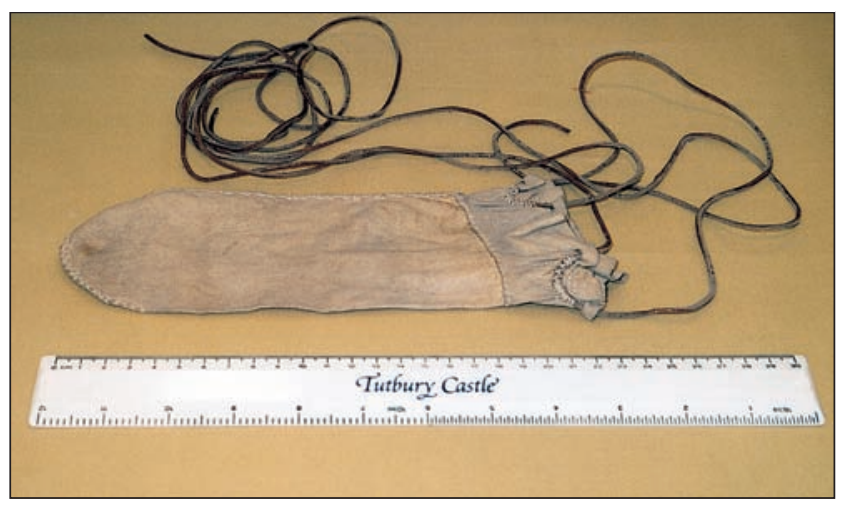

Figure 3 Leather condom constructed on the basis of known gut designs for the 'Pistol Pocket'.

This experiment does not of course prove that lemons and limes were used as a contraceptive device in the 16th century, but it does demonstrate that they could have been and that they were capable of acting as a fairly competent contraceptive.

It would be perfectly acceptable to have this kind of citrus fruit in the household and it would not cause any scandal. I did not say it was cheap, however. Such fruit was actually very expensive, and the highest cost I have calculated in the 1580 s during the winter months was the equivalent of $£ 20$ per item of fruit if you lived in the Midlands. Imagine transporting the fruit during the icy winter months where it had to be moved across dangerous icy seas and over rutted roads by carts to the centre of England. I kept one batch of fruit in my cellar for 6 weeks - as the Elizabethans would have done - and found that the juice remained, although the fruit changed colour, and the wall of the fruit was more inclined to collapse.

We have no idea who first thought of this, like many other things in history, but it appears that many merchants brought their wives with them from foreign shores to meet their families and enjoy English hospitality. Despite the language barriers, the wives may well have been able to communicate this simple idea from one nation to another. There is also evidence that practices in the stews (brothels) eventually filtered out to the general public, with the husband telling the wife that "a friend of a friend had told him when he had visited a brothel ...".

\section{Ancient prophylactics}

In the British Museum there is a rather fascinating cupboard known as a 'secretum' containing some of the more salacious items from collections across a broad time span. One of the items is a beautifully stitched gut condom of a sizeable proportion (Figure 2). Around the top are ribbons threaded, still bright pink, to tie the device to the penis. Light as gossamer, the gut has been carefully stitched to shape and dried.
Linen condoms were known in the 1500s and a leather version was also known (i.e. not all condoms were made of gut). One name given to leather condoms was the 'Pistol Pocket', the pistol being a common description of a penis. Mention of Falstaff's crony, 'Pistol', must have caused a roar of laughter in 'The Globe' theatre. I have had a leather condom produced based on known gut designs and erotic literature of the day (Figure 3). They would be kept in oil for two reasons: as extra protection against leakage via the stitches and also to allow penetration to be comfortable. The latter point is particularly relevant when the prophylactic has been washed - it becomes stiff as a board.

It must be understood that condoms were really intended for protection against the vicious 'French Pox', with the contraceptive value being a secondary benefit.

\section{Role of the Church and conscience}

The Catholic Church accepted the so-called "withdrawal method' and gradually there arose an understanding of fertile times, generally believed to be a couple of weeks after the 'moon flux,' although some still believed fertility to be during menstruation. Some readers may wonder that in Catholic Europe there was contraception at all, never mind it being in fairly common use. There are two things to consider here: first, that the Bishops of Winchester collected the taxation on official brothels for many hundreds of years, and second, the use of contraception still had a sense of the forbidden under Protestant rule.

The truth is, history, as now, is populated with lovers, official and illicit. It is all a matter of conscience - ask Henry VIII!

\section{Future articles}

Readers interested in finding out more for themselves about the topics covered in this article should consult some of the publications listed in the Bibliography.

The next article in this series will cover sexual behaviour in the 16th century, when sex in the marriage bed, in the brothel and in gay relationships (both male and female) will be examined.

\section{Acknowledgements}

The author would like to thank the following individuals for their help and advice: Dr R Arnott, Sub-Dean of Medicine and Director, The Medical School, University of Birmingham, Birmingham; Mr A D G Roberts, MD, FRCOG, Queen's Hospital, Burton-upon-Trent; Prof. Trevor Brown, Chemistry Department, University of Derby, Derby; and Dr G Williams, Curator, British Museum, London, UK.

\section{Bibliography}

There are a large number of books on the 16th century, some more relevant (and competent) than others. Here is a small selection to add to my series' recommended reading list.

1 Burford EJ, Wooton Joy. Private Vices - Public Virtues. London. UK: Robert Hale, 1996.

2 Eccles, Audrey. Obstetrics and Gynaecology in Tudor and Stuart England. London, UK: Croom Helm, 1982.

3 Sloan AW. English Medicine in the Seventeenth Century. Durham, UK: Durham Academic Press, 1996.

\section{About the Author}

Lesley Smith is an Elizabethan historian, currently studying for the degree of MPhil in the History of Medicine at Birmingham University Medical School. She has appeared in 16 television programmes including Tony Robinson's The Worst Jobs in History, and is currently working on an eight-part 1-hour major series on the Private Lives of Women.

Lesley is well known as a public speaker and regularly startles her audiences when appearing in full Elizabethan costume and the dead-white authentic make-up of the 1580 s. Lesley's humorous and powerful delivery is encouraging many health professionals to find out more about the root of their profession. 